\title{
Uso de Questionários no Moodle como Apoio para Aprendizagem
}

\author{
Elisabeth Andreoli de Oliveira \\ Instituto de Física da Universidade de São Paulo \\ * Autora para correspondência:
}

\section{RESUMO}

Atualmente uma das grandes dificuldades dos alunos na cidade de São Paulo é a mobilidade, pois diariamente passam em média de três a quatro horas no transporte. $\mathrm{O}$ uso da plataforma Moodle permite a disponibilização de textos, notas de aula e material didático de apoio, que podem ser consultados em telefone celular ou tablets. Os questionários têm sido utilizados como ferramenta auxiliar para permitir ao aluno manter um ritmo de estudos e revisar os temas que estão sendo tratados em sala de aula. As questões são formuladas para focalizar a atenção em conceitos oriundos da Física, e o professor pode acompanhar o desempenho coletivo, identificando aspectos a serem retomados em sala de aula, com discussões em grupos, orientadas por ele. Na avaliação do aluno, questões conceituais estão presentes, além das questões tradicionais que exigem técnicas de resolução de problemas. Pretende-se assim trabalhar habilidades de argumentação e dissertação sobre temas científicos, necessárias a futuros professores e pesquisadores.

Palavras-Chave: Moodle; Testes Conceituais.

\begin{abstract}
Currently one of the major problems of the students in the city of São Paulo is the mobility since they spent daily, on average three to four hours of transportation. Moodle platform enables the provision of texts, notes, and teaching materials, which can be accessed by cell phone or tablets. The questionnaires have been used as auxiliary tool to allow the student to maintain a pace of study and review the issues being dealt with in the classroom. The questions are designed to focus attention on concepts from Physics and the teacher can follow the collective performance by identifying aspects to be taken back into the classroom, with discussions in groups, guided by the teacher. Conceptual issues are part of the evaluation of the student as well as solve problem techniques. The purpose of this action is to develop skills of argumentation and dissertation on scientific subjects for future teachers and researchers.
\end{abstract}

Keywords: Moodle; Conceptual Tests.

Atualmente uma das grandes dificuldades dos alunos na cidade de São Paulo é a mobilidade. Para muitos, mesmo morando na região da Grande São Paulo, o tempo diário gasto em transporte público é da ordem de três a quatro horas. Esse problema é mais grave para os alunos que frequentam o noturno, pois a disponibilidade de tempo para estudo é ainda menor.

Uma das estratégias adotadas para as disciplinas de Ótica $(2014,2015)$ e Oscilações e Ondas (2013, 2014, 2016), do curso de Licenciatura em Física, foi o uso intensivo da plataforma $M_{o o d l e}{ }^{1}$ para apoio ao ensino. Materiais de apoio, tais como textos, notas de aula, listas de exercícios, e vídeos, são disponibilizados para que possam ser consultados e/ou visualizados mesmo em um telefone celular. A plataforma permitiu ainda a criação de algumas tarefas, que o aluno realiza fora da sala de aula (individualmente ou em dupla), e questionários. $\mathrm{O}$ documento final com a tarefa executada é submetido usando recursos da plataforma.

As tarefas mais simples consistem, em geral, de exercícios. Esse exercício pode ser um problema, com aplicações dos conceitos tratados em sala, questões sobre algum experimento de demonstração realizado em sala, ou ainda pode exigir que 
o aluno assista a um vídeo, ou use um aplicativo com simulação e responda a algumas perguntas sobre o que foi observado, aplicando conceitos para interpretar suas observações. Essas tarefas simples são individuais, e o prazo para realização é de três a quatro dias.

Outro tipo de tarefa consiste em propor um problema mais complexo, que pode ser feito em duplas. Como exemplos de tarefas desse tipo, pode-se citar a resolução de uma equação diferencial linear utilizando o método numérico, ou o exercício de explicar a formação do arco-íris ou de miragens. Uma tarefa mais complexa pode ser subdividida em etapas, sendo a primeira realizada em sala para contextualizar o problema e indicar os conhecimentos necessários. As etapas consistem de procedimentos ou questões que envolvem maior dificuldade, e são realizadas fora do período de aula. O prazo para essas tarefas pode chegar a duas semanas. Com as tarefas mais complexas, os alunos são incentivados a pesquisar em outros livros, além do livro-texto e a discutir suas ideias.

Um recurso muito valioso, que tem sido utilizado nas duas disciplinas, consiste na aplicação de questionários de múltipla escolha, ou de associação, que em geral devem ser respondidos no período de dois a três dias. O questionário aborda temas tratados anteriormente no curso e traz apenas questões conceituais (MAZUR, 1996), que não exigem cálculos.

Abaixo são apresentados quatro exemplos de questões propostas aos alunos:

A posição de uma partícula oscilando no eixo x é dada no gráfico ao lado. No instante $t=A$ :

a) $A$ velocidade é nula e a aceleração é negativa.

b) A velocidade é negativa e a aceleração é nula.

c) A velocidade é nula e a acelerasão é positiva.

d) A velocidade e a aceleracãa são negativas.

e) $A$ velocidade é positiva e a aceleração é nula.

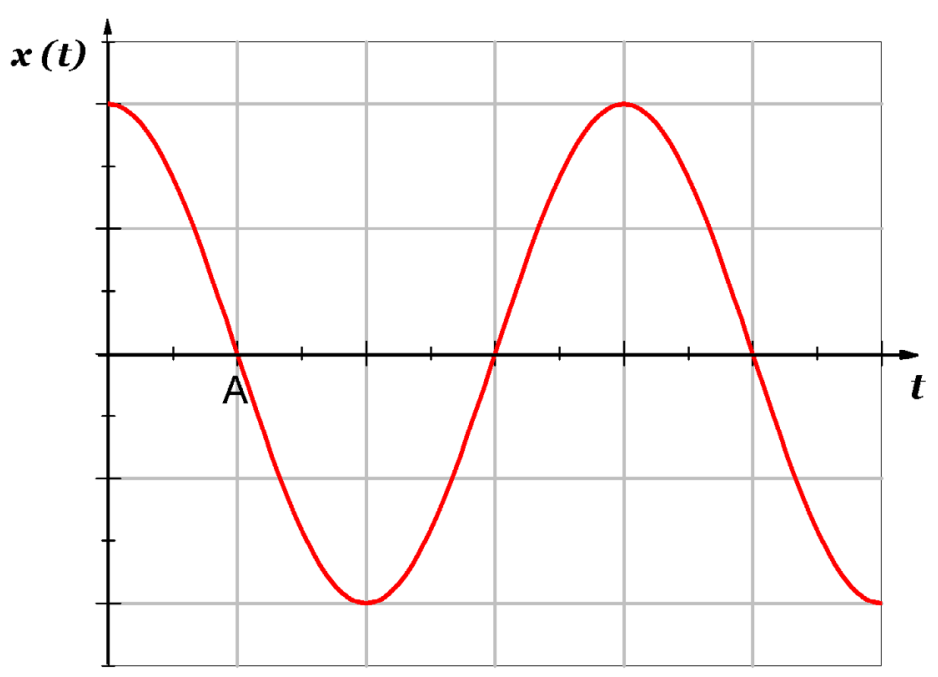

A figura abaixo ilustra a propagação de luz em uma fibra ótica. Identifique abaixo as afirmações corretas.

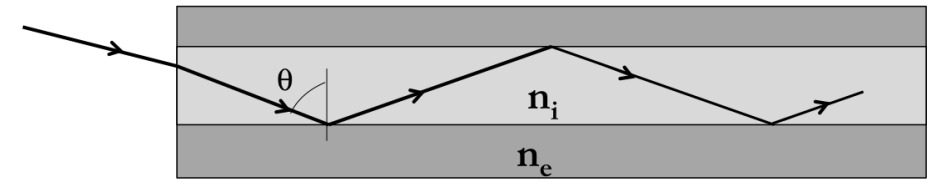

a) $O$ ângulo de incidência $\theta$ é menor que o ângulo crítico.

b) 0 indice de refraşão ni é maior que ne.

c) $O$ indice de refracão ni é menor que ne.

d) $O$ ângulo de incidência $\theta$ é maior que o ângulo crítico. 
A imagem de um objeto formada por uma lente tem aumento transversal igual a -3. Podemos afirmar que:

a) a lente dever ser convergente.

b) a imagem é invertida.

c) a lente deve ser divergente.

d) a imagem é real.

Uma onda sonora propagando-se no ar penetra na água. O que se altera na mudança de meio?

a) o comprimento de onda.

b) a frequência.

c) a velocidade de propagacãa.

A proposta do questionário é permitir que o aluno faça uma revisão dos assuntos abordados nas aulas anteriores e responda a ele ao se sentir preparado para tal. Esses questionários apresentam duas ou três questões, cada uma pertencente a uma categoria de conceito. As questões são sorteadas entre várias que compõem uma categoria, e a ordem das alternativas é aleatória. O tempo de resposta para cada questão é da ordem de dois a três minutos, e o aluno tem a possibilidade de fazer duas tentativas, ficando com a maior nota entre as duas tentativas ${ }^{2}$.

Após ter respondido as questões, o aluno é informado sobre os acertos ou erros em cada uma delas. Assim, ele pode optar por adiar uma segunda tentativa, revisando conceitos sobre os quais tenha dúvidas.

O professor pode acompanhar o desempenho dos alunos individualmente ou no conjunto, identificar questões com maior índice de erro ou acerto, ou que não tenham um bom índice de discriminação e devem ser reformuladas. Essa avaliação permite ao professor perceber problemas de compreensão que eventualmente permanecem e retomá-los em sala de aula. Algumas vezes, os próprios alunos identificam os pontos a serem retomados e solicitam ao professor uma discussão em sala de aula. Questões conceituais, na forma dissertativa, fazem parte das provas de avaliação individual, e o aluno deve argumentar para justificar suas respostas.

As notas obtidas nas atividades propostas no Moodle e realizadas fora da sala são parte da avaliação individual. Com essa proposta, pre- tende-se que o aluno seja levado a refletir sobre aspectos mais conceituais, em geral deixados de lado em favor de aspectos mais operacionais, e que seja capaz de utilizar o conhecimento científico para construir argumentação (NATIONAL RESEARCH COUNCIL, 2000; HALLOUN \& HESTENES, 1985).

\section{Considerações Finais}

As estratégias aqui apresentadas fizeram parte de uma proposta mais ampla de propiciar uma participação mais ativa dos alunos em sala de aula, promovendo discussões, e reflexões sobre situações em que normalmente o bom senso não é compatível com os conceitos físicos. $\mathrm{O}$ fato de que as avaliações contemplavam questões conceituais, que exigiam justificativas, levou os alunos a exporem suas dúvidas, para que pudessem ser esclarecidas. Nessas discussões, muitas vezes surgiram questões fundamentais da Física e a percepção de como se constrói o conhecimento científico.

\section{Notas}

1 http://disciplinas.stoa.usp.br.

2 Foi criado um banco de questões para cada uma das disciplinas, separadas por categorias, e esse material foi compartilhado com professores que passaram a ministrar a disciplina em outros semestres.

\section{Referências Bibliográficas}

HALLOUN, Ibrahim Abou \& HESTENES, David. "Common Sense Concepts about Motion". American Journal of Physics, vol. 53, n. 11, p. 1049, 1985. 
MAZUR, Eric. Peer Instruction: A User's Manual. Upper Saddle River, N.J.: Prentice Hall, 1996. NATIONAL RESEARCH COUNCIL. How Press, 2000.
People Learn: Brain, Mind, Experience, and School: Expanded Edition. Washington, DC: The National Academies

Publicado em 22/12/2017. 